\title{
Rogelio de la Mora Valencia y Hugo Cancino Troncoso (coords.), Aspectos de la modernidad latinoamericana: rupturas y discontinuidades, Xalapa, Ver., Universidad Veracruzana, 2017.
}

La obra Aspectos de la modernidad latinoamericanas: rupturas y discontinuidades” coordinada por Rogelio de la Mora Valencia y Hugo Cancino Troncoso, podemos enmarcarla en el debate nunca concluido sobre la modernidad en América Latina, si bien el propósito de los autores no es entrar directamente en esta dialéctica y por eso encontramos solo unas pocas alusiones a la cuestión teórica.

El libro está organizado en seis apartados: los intelectuales, las mujeres en el trabajo intelectual y cultural, pueblos indígenas, Guerra Fría y modernidad, Religiosidad e Identidades que recogen estudios de casos muy diferentes entre ellos en el espacio y en el tiempo, sin embargo, con excepción de algunos casos, la obra se concentra en el siglo XX y en parte del XIX.

Los autores no se detienen en la abstracción conceptual de los procesos de modernización, que hasta hoy en día ha engendrado resultados limitados, sino escogen sabiamente un enfoque más novedoso del simple discurso crítico para centrarse en una más fructífera investigación empírica orientada en ámbitos específicos.

El término "modernidad" que aparece en el titulo remonta al debate de los años ochenta, cuando por primera vez empezó a ser usado en México, sin embargo, el libro deja a un lado la clásica énfasis de un discurso fundamentado sobre asociaciones tal cuales modernización /desarrollo económico o la más recién modernización /democracia que ha sido considerada un requisito indispensable de la modernidad latinoamericana. Si bien estos temas afloran en algunos ensayos, la obra se enfoca en temas innovadores que son objeto del actual debate iniciado con el nuevo milenio: identidades, ciudadanía, genero, heterogeneidad y diversidad cultural.

La riqueza de los casos tratados nos da cuenta de los múltiples procesos de la modernidad latinoamericana, una modernidad en permanente devenir histórico, que podemos imaginar más como un proyecto en itinere, con infinitas variaciones que se manifiestan en experiencias culturales sedimentadas y en prácticas sociales, como ocurre por ejemplo en el universo de la religión, de la cultura indígena o de las estructuras políticas. 
Uno de los meritos de la obra es restituir al lector la imagen fragmentada de una modernidad que no puede reducirse a un único camino y que abre espacio a una infinidad posibles de resultados finales. De esta forma, las polifacéticas modernidades de los casos tratados en el texto nos remiten a la realidad de una región que no existe en cuanto sujeto unitario: así como existen muchas Américas Latinas existen muchos caminos a su modernidad y modernización. Gracias a esta metodología los ensayos del libro sobrepasan una simple aplicación de modelos externos y el dominio de la cosmovisión europea para escribir una historia propia de la región. La pregunta subterránea que cruza la obra parece ser: ¿existe un camino propio de la modernidad latinoamericana? A la cual los autores contestan con un relato que evidencia las rupturas y las discontinuidades del camino.

Inevitablemente el libro marca unas etapas de la modernidad, sin embargo, los autores no ceden a la fácil tentación de trazar un camino histórico evolutivo, quizás por esta razón la obra no tiene un orden cronológico, y no caen en la clásica dicotomía entre modernidad y tradición que determinaría una línea evolutiva trazada a priori del devenir histórico. Más bien la obra da cuenta de momentos, de procesos que marchan a veces por avances y retrocesos donde modernidad y tradición se entremezclan, sin que la primera sustituya la segunda, en una síntesis original hecha de una "multiplicidad de lenguajes".

Todo esto enmarcado al interior de un proceso histórico de modernización que es común a todo occidente y donde emergen evidentes interrelaciones entre Europa y América Latina, sin que esto signifique una mera repetición o transferencia de una realidad externa en un contexto ajeno.

Este aspecto lo podemos apreciar a lo largo del libro en algunos ensayos de historia intelectual como por ejemplo, "Recepción y representación de la obra de Ignacio de Lúzan en México, 1900-1930”, de Rogelio de la Mora Valencia y Rómulo Pardo Urías, que nos da cuenta de cómo un mismo hecho cultural, el recuerdo de Luzán en España y México, tiene interpretaciones distintas y como dice al autor "mediadas por procesos ideológicos y nacionales diferentes": en el contexto español el resurgimiento de la hispanidad y en el mexicano por el historiar las herencias culturales españolas. Se trataría "de una herencia cultural trasatlántica” aunque, como expresan los autores, hay que preguntamos "hasta qué punto es una herencia de alcance hispanoamericano”. 
A lo largo del libro si bien se percibe el deseo de restituir un camino proprio a la región, los autores no caen en la trampa de analizar los fenómenos en forma autorreferencial, como si se tratara de un mundo cerrado y redoblado en sí mismo. Así por ejemplo en el ensayo “¡Por la libertad y la justicia! El caso de Sacco y Vanzetti en la Revista Claridad', que narra las vicisitudes de dos obreros italianos migrantes en Estados Unidos condenados a la silla eléctrica, la autora no olvida de insertar América Latina en el efervescente contexto internacional de las primeras décadas del siglo pasado ricas de despertar de ideas. La autora argumenta que gracias al suceso de estos obreros se crearon nuevos vínculos internacionales no solo entre intelectuales sino también entre sindicatos y asociaciones obreras lo que permitió "una mejoría en la movilización social y riqueza intelectual”. Los autores latinoamericanos que escribieron en la Revista Claridad sobre Sacco y Vanzetti “se identificaron con las propuestas de la modernidad, pero al mismo tiempo intentaron compréndela y transmitirla con lecturas regionales y nacionales probablemente con la intención de ubicarse con una identidad propia”.

En el viaje al interior de este camino hacia la modernidad, hecho también de redes tejidas entre las dos orillas del Atlántico resurge así la eterna duda: ¿es posible separar dos caminos distintos de modernidad del mundo occidental?

Pregunta que reaparece con la lectura del interesante ensayo de Gilmar Mascarenhas sobre integración nacional y popularización del futbol, con el cual nos acercamos a la cultura popular urbana, una de las expresiones más acabadas de la modernidad latinoamericana en los años ’30 - ‘50 del siglo XX marcados por procesos de state-bulding y nation-building, por innovaciones políticas, sociales y económicas.

El futbol, como explica el ensayo, era una novedad cosmopolita de origen europea que se popularizó en América del sur llegando a desarrollar un importante papel en la construcción de la identidad nacional, y que no acaso hoy en día en una nueva época de "futbol globalizado" se relaciona con los procesos ya desgastados de identidad nacional.

El tema de la identidad es un tema relevante en la obra, cruza varios ensayos y se constituye en un apartado proprio. En el ensayo "La historia madre en América, la deconstrucción del coloniaje de la memoria y de los imaginarios...." se expresa la necesidad de de-construir la memoria y los imaginarios lo que implica una "deconstrucción del pensamiento hegemónico occidental y la construcción de pensamiento proprio" al fin de inaugurar en América Latina la 
"Historia Madre". Retomando los clásicos estudios de Dussell el ensayo critica a la modernidad subrayando la necesidad de construir una nueva visión: la llamada transmodernidad, término usado en lugar de posmodernidad. Emerge aquí la crucial cuestión de la pluralidad de identidades en el escenario de la modernidad, un tema de particular relevancia en un continente que sigue siendo plural, culturalmente diverso y donde conviven etnias, modos de vidas diferentes y muchas religiosidades. Así, por ejemplo, la secularización no ha implicado el fin de la religión sino más bien la perdida de una cierta visión religiosa del mundo y un florecimiento del pluralismo que hoy en día se expresa en el proliferar de nuevas religiosidades populares. Obviamente, cada una de las formas en las cuales se presenta un fenómeno no puede por sí sola representar el todo. En efecto el ensayo dirige su atención hacía lo local y lo regional de la realidad contemporánea con sus propias identidades plurales en el marco de la denominada transmodernidad.

La reflexión sobre la identidad entendida como un proceso de construcción continua por medio de distintos significantes, tal cuales etnia, sexualidad, religión o cultura, emerge también en el novedoso texto "Emprendimiento con identidad mapuche: el caso de las mujeres mapuches de Chile" que nos revela los cambios que la modernidad globalizada ha llevado en el ámbito privado de la vida de las personas, en las relaciones interpersonales, en el estilo de vida y en los patrones de consumo. Sin embargo, la autora nos enseña que las mujeres Mapuches no solo ascienden a nuevos roles empresariales sino fortalecen, al mismo tiempo, su vinculación con la cultura y la identidad preservando la continuidad socio-cultural en sus comunidades.

El tema de la convivencia de etnias, de modos de vidas diferentes, y del pluralismo, lo encontramos también en "Inclusión, exclusión y territorialidad indígena en Colombia a fines del siglo XX: una perspectiva histórica”, un ensayo que debate una temática muy actual y que nunca ha dejado de ser investigada en relación con los procesos de la modernidad: la exclusión social. Se trata da un aspecto que no ha sido superado y los mismos estados "modernos" nacidos con los procesos de democratización se han construidos sobre la exclusión social.

En efecto, la última década del siglo pasado ha sin duda constituido un momento de ruptura y discontinuidad del cual ha surgido una América Latina nueva, o por lo menos en parte nueva, en lo económico en lo social y en lo político. La región ha sido cruzada por intensos procesos 
de modernización institucional expresados por renovadas constituciones, que a veces han sido a la vanguardia mundial. Sin embargo, aparece el dilema de una modernidad caracterizada por la brecha entre los países legales y los países “reales” que muestran el rostro de aquella América Latina tradicional que forma una síntesis original donde sobreviven figuras supuestamente premodernas, como el caciquismo, el clientelismo, el compadrazgo, que sin embargo a su vez han sido cruzadas ellas mismas por procesos de modernización.

El caso colombiano tratado evidencia el indiscutible avance jurídico introducido por la constitución política al reconocer el estado multiétnico, sin embargo, las nuevas garantías concedidas a las comunidades se dieron a partir de conceptos semánticos pensado por el gobierno central y ajeno a las comunidades con el resultado de un constitucionalismo construido sobre la exclusión.

No podemos olvidar el tema del estado que reaparece en varias semblanzas a lo largo de la obra, argumento que nunca ha dejado de despertar el interés de las ciencias sociales y que hoy se interroga acerca de su papel en un contexto de modernidad globalizadora, que requiere una nueva reflexión y nuevas preguntas.

A lo largo de la obra el estado nación emerge en relación a su rol centralizador o al surgimiento de movimientos emancipadores, como el feminista, y también a las políticas educativas. En el apartado "Mujeres en el trabajo intelectual y cultural" se relatan las vicisitudes de las políticas educativas que permitieron el ingreso de las primeras mujeres en las universidades mexicanas al finalizar del siglo XIX, lo que rescata el aspecto de las luces porfirianas, muchas veces oscurecidas por la historia política. La obra rescata la importancia de las políticas educativas de final del siglo XIX en México y muchos otros países (Brasil, Chile, Cuba, Argentina) subrayando que jugaron un papel fundamental para la causa de las mujeres, más que el conseguimiento del derecho al voto. Al mismo tiempo podemos otra vez apreciar a lo largo de los ensayos una contemporaneidad con los paralelos procesos ocurridos en el "otro occidente".

Como nos explican Rogelio de la Mora y Romúlo Pardo Urías, el estado nación se configura también como el principal portador de memoria cultural, inscrita en representaciones simbólicas, instituciones educativas, culturales, científicas que trascienden diversas épocas. El estado es también constructor de la cultura nacional. El ensayo "La cultura brasileña de fiesta: 
los intelectuales y la celebración del Sesquicentenario de la Independencia Brasileña (1972)” a través del análisis de la publicación “Atlas cultural do brasileña” (obra conmemorativa por el 150 aniversario de la independencia) arroja luz sobre el vínculo entre el ámbito político y el mundo intelectual. Esta investigación nos da cuenta de la re-dirección política de la cultura adquirida durante la dictadura que vio la participación activa de los intelectuales al régimen militar rescatando ideas fuerzas del periodo getulista tal cuales "tradición”, "identidad nacional”, "pasado histórico", "memoria nacional”, en continuidad con el proyecto de los modernistas.

No hay que olvidar la importante etapa de la Guerra Fría, que tiene apartado propio en la obra, una época de nuevas ideologías y de revoluciones en América Latina, cuando los mismos regímenes militares, que a menudo se autoproclamaban revolucionarios, ambicionaron a implantar un orden nuevo acabando así por mostrar la cara más terrible del progreso, o de la falta de progreso. La Guerra Fría, como nos explica claramente Hugo Cancino Troncoso en “Socialistas y comunistas chilenos durante la Guerra Fría, 1945-1970”, se internalizó en todas las sociedades de América Latina y jugó un rol fundamental en los conflictos políticos nacionales generando alianzas políticas inéditas, como la de los partidos socialistas y comunistas chilenos a pesar de sus diferentes posiciones con respecto al conflicto bipolar.

En fin, desafortunadamente no es posible detenerse sobre todos los interesantes y sugerentes ensayos que nos ofrecen una imagen lograda de este incesante proceso de modernidad que ha sido el siglo XX, felicito a los coordinadores y a todos los autores y sobre todo les recomiendo la lectura del libro.

Tiziana Bertaccini Dipartimento di Culture Politica e Società Università degli Studi di Torino tiziana.bertaccini@unito.it 